\title{
Injury Pattern in Fatal Cases of Stab Wound
}

\author{
Misbah Ul Hoq Chowdury ${ }^{* 1}$, Ali Md. Shariful Alam Rubel ${ }^{2}$, Md. Samir Uddin ${ }^{3}$, Kanta Deb ${ }^{4}$, \\ Chowdhury Rifat Jahan ${ }^{5}$
}

\begin{abstract}
Introduction: Stabbing is the most common method of homicide as like as other parts of the world. Precise examination of stab wound along with the type of other wounds considering their site, shape, number and orientation of the wounds in relation to each other etc. provide a number of clues which may be of paramount importance in reconstruction and interpretation of the whole events. Materials and Methods: This is a retrospective study carried out in Forensic Medicine Department of Sylhet M.A.G. Osmani Medical College, Sylhet from July 2010 to June 2011 and in the year of July 2017to June 2018 to observe different patterns of injuries in fatal cases of stab wound. 20 autopsies were included in this study using random sampling. Results: Male $(90 \%)$ are more victimized than female. The pattern of injury that found to be most common is the penetrating wound of the chest injuring either lung or heart. Second most common injury pattern is the penetrating wound of the chest or abdomen injuring eitherstomach or liver.Another pattern is widely scattered multiple stab wounds both on front and back of the body and the fourth pattern is stab wound of the lower limb causing division of a major blood vessel. Conclusion: The stab wound is deeper than it is long or wide. This means depth is the greatest dimension in case of Stab wound and that is where the danger lies as it is evident in this study.
\end{abstract}

Keywords: Stab wound, Fatal cases, Injury pattern.

Number of Tables: 03; Number of References:09; Number of Correspondence: 05

*1. Corresponding Author: Dr. Misbah UI Hoq Chowdury

Assistant Professor

Department of Forensic Medicine

Parkview Medical College, Sylhet.

Email: misbahwasim123@gmail.com.

Mobile : 01732-860455

2. Dr. Ali Md. Shariful Alam Rubel MBBS, DFM

Forensic Expert.

3. Prof. Dr. Md. Samir Uddin

Department of Anatomy

Parkview Medical College, Sylhet.

4. Dr. Kanta Deb

Assistant Professor

Department of Forensic Medicine

Sylhet Women's Medical College, Sylhet.

5. Dr. Chowdhury Rifat Jahan

Associate Professor

Department of Physiology

Parkview Medical College, Sylhet.

\section{Introduction}

A stab wound is a wound which is produced when force is delivered along the long axis of a narrow and pointed object, such as knife, dagger, sword, chisel, scissors, nail, needle, spear, arrow, screw driver etc. into the depths of the body ${ }^{1}$.

The wound is deeper than it is long on the skin surface $^{2}$. Depth is the greatest dimension of this wound and according to how much depth an object has traversed. These are two types. When an object enters a body cavity or viscus, it is called penetrating wound and when an object enters body cavity or viscus from one side and comes out from the other side then it is called perforating wound.

Stabbing is the most common method of homicide in developing countries like Bangladesh, due to quarrel, overpopulation, joblessness, political unrest, poverty, family dispute, etc ${ }^{3}$. All the above mentioned factors lead to a violence which may result ultimately in a fatal outcome.

Stab wound is of major importance in Forensic Medicine as this is a common method of homicide and most deaths from stab wounds are homicidal ${ }^{3,4}$. The basic criteria of the wound-depth indicate about the source of the fatal outcome. Homicidal stab wound need not to be multiple, widely distributed and deep.

Always, it can be single on a vital spot and that is enough to bring a fatal outcome. The sign of struggle sometimes present and in such case there are multiple wounds found on the body.

Sometimes the other wounds found along with stab wound clearly define the nature of the wounds, especially when those other wounds are also present on the vital spot of the body which has become evident in this study. On the other hand, the orientation of the wounds in relation to each other also indicates the intention of the assailant and thus the nature.

\section{Materials and Methods}

This study is carried out in Forensic Medicine Department of Sylhet M.A.G. Osmani Medical College, Sylhet from July 2010 to June 2011 and in the year of July 2017 to June 2018 to observe different patterns of injuries in fatal cases of stab wound.

Twenty (20) autopsies were included in this study using random sampling. 
Necessary information gathered from police inquest report and accompanied friends, neighbors and relatives.

The study based on physical examination using the usual methods and instruments.

No special technique or incision was employed. The variables that are analyzed were sex, age, injury pattern and vital organ injured.

\section{Results}

Among the 20 deceased, 18 were male and 2were female and the male female ratio was 18:2. Age of them ranged between 11 years to 52 years. Among 20, 16 were adult and 4 were children (below 18 years). Sex and age distribution are shown in table I \& II.

Table -I: Sex distribution.

\begin{tabular}{lcc}
\hline \multicolumn{1}{c}{ Sex } & Number & Percentage \\
\hline Male & 18 & $90 \%$ \\
Female & 02 & $10 \%$ \\
\hline \multicolumn{3}{c}{ Total $=20$} \\
\hline
\end{tabular}

Table-II: Age distribution.

\begin{tabular}{rcc}
\hline Age & Number & Percentage \\
\hline Children (below 18 years) & 04 & $20 \%$ \\
Adult (Above 18 years) & 16 & $80 \%$ \\
\hline Total $=20$ \\
\hline
\end{tabular}

As mentioned earlier, the pattern of injuries that found to be most common is the Penetrating type of Stab wound of the chest with the involvement of either heart or lung. Second most common injury pattern is the Penetrating type of Stab wound of the chest or abdomen injuring either stomach or liver. Another pattern is widely scattered multiple stab wounds both on front and back of the body and the fourth pattern is Stab wound of the lower limb causing division of a major blood vessel. (Table III).

Table-III: Distribution according to the injury pattern.

\begin{tabular}{lc}
\hline Injury pattern & Percentage \\
\hline $\begin{array}{l}\text { Penetrating type of Stab wound of the } \\
\text { chest with the involvement of either heart } \\
\text { or lung with an oblique direction from } \\
\text { left to right }\end{array}$ & $50 \%$ \\
\hline $\begin{array}{l}\text { Penetrating type of Stab wound of the } \\
\text { chest or abdomen injuring either stomach } \\
\text { or liver with an oblique direction from } \\
\text { left to right and/or from above } \\
\text { downwards }\end{array}$ & $30 \%$ \\
\hline $\begin{array}{l}\text { Widely scattered multiple stab wounds } \\
\text { both on front and back of the body }\end{array}$ & $10 \%$ \\
\hline $\begin{array}{l}\text { Stab wound of lower limb causing } \\
\text { division of a major blood vesselOblique } \\
\text { from above downwards }\end{array}$ & $10 \%$ \\
\hline
\end{tabular}

\section{Discussion}

Depth, direction, site, shape, number and orientation of the wounds in relation to each other constitute an injury pattern. The stab wound is deeper than it is long or wide on the skin surface ${ }^{1,2} \& 5$. This means depth is the greatest dimension in case of Stab wound ${ }^{6}$ and that is where the danger lies as it is evident in this study.

When force is delivered along the long axis of a narrow and pointed object, such as knife, dagger, sword, chisel, scissors, nail, needle, spear, arrow, screw driver into the depths of the body, it is not necessary that death will occur after a vital organ is injured but if a major blood vessel is divided in the limb, severe bleeding can lead to the ultimate fatal outcome.

The most important fact that should be in mind is the viscera of a dead body on the autopsy table are not in the same position as when the same person was alive and in standing position or was bent over in a state of emotional tension at the time of an assault.

During fight, fright and flightthe victim may be moving or changing position in a variety of postures which change by the second ${ }^{1}$. So, it is unpredictable as to which organ to be found injured in case of stab wound when the angulations of the track is sufficient and for this reason although the entry point is on the chest, ultimately the abdominal organ found to be injured traversing through the diaphragm and vice versa which is evident in this study. The unpredictability seems much more true as it should be in mind that the whole process of stabbing a person is not a static event, but a dynamic event as mentioned above and there are a lot of interactions between the victim and the assailant unless it is sudden surprised attack which is not uncommon. The organ just beneath the skin wound is not the organ to be ultimately injured and the oblique direction of the stab wound is a steady finding. Direction can provide valuable clue as to the relative position of the assailant and the victim. Determination of the direction relies on both the appearance of the skin wound and the track in the deep tissues ${ }^{5}$. More information whether there is any leverage or angulations in the middle of the track, that means changing direction without withdrawal of the weapon completely, can be found by careful anatomical dissection during autopsy examining tissues in layer by layer from the surface downwards. The damage to deep structures and organs compared with the position of the surface wound and a clear idea can be found about the direction. Attempts have made to delineate the track of a stab wound before dissection either by filling the defect with a radio-opaque fluid before taking X-rays or by filling with a plastic or even metallic substance that will harden to form a cast. In practice, these methods appear to have little advantage over careful dissection ${ }^{5}$. The most common direction is from left to right which obviously indicates that the assailant is a right-handed person as it is the inherent natural tendency of a right-handed person to stab from left to right direction when standing in front of the victim. 
A common form of homicide is a stab wound of the chest which penetrates the heart or involving lungs $7 \& 1$. Stab wound of the abdomen involving liver or stomach is another site.

An unusual site for stab wound is lower limb, even considering the defense wound. Supported by history and also other study this unusual pattern seems to be due to the posture of the victim, sudden provocation, motive to make the escape easy ${ }^{3}$.

Sometimes the right ventricle and sometimes the left ventricle found to be penetrated but in both cases large amount of clotted blood are found in the chest cavity indicating copious bleeding from stab wound. This also indicates the absence of the muscular 'self-sealing' effect which is also supported by the absence of any treatment history and that means the death was not delayed.

The number of stab woundalong with the site is an important factor in determining the nature of the wound. The multiple numbers of wounds that are widely scattered and deeply penetrating when present on the vital site of the body such as chest, indicates about the intention of the assailant to confirm death and thus the nature of event. The multiple numbers of other wounds away from the site of fatal injury indicates that there was a struggle for a while and the event was not a surprise attack. It is said that most deaths from Stab wound are homicidal, especially when found in the inaccessible site but most of the homicidal stab woundalso may be found in the accessible site as evident in this study as well as other studies $3,8 \& 9$.

For most of the stab wounds all over the world and for several decades' chest and abdomen remain the most commonsite for fatal stab wound ${ }^{3,4,8}$ \& 9 .

The other types of wound along with the stab wound indicate not only the nature but also help to reconstruct the event. Multiple blunt force injuries like abrasion, bruise and laceration on different sites of the body indicate most of the times the resistance and the forceful restrain waiting for final blow as evident in this study. Other sharp force injury along with the stab wound indicates not only the nature of the whole event but also the intention to confirm the death, especially when the other wound is more severe in nature and severing a major vessel.

The shapes that found in this study on skin wound are spindle shape and oval shape. The spindle shaped skin defect is found mostly $(80 \%)$ as it is found also frequently by the forensic pathologists where both ends of the defect appear sharply cut coming to a fine ' $\mathrm{V}$ ' point at the extremities. The tapering and the sharpness of the blade at the edges create this spindle shape of the skin defect well known all over the world.

The weapon almost always a dagger or knife. Unfortunately, this does not necessarily indicate that a knife with two sharp edges was used, as the skin often splits behind the blunt edge to produce a symmetrical appearance ${ }^{5}$.
On other hand the oval shaped skin defect obviously indicates the weapon of blunt edges even considering the anatomical position of the skin defect in line or across tension of Langer's lines, although there is opposite factor of skin elasticity decreasing the size of defect and contributing also to modify shape complicating the whole scenario of determining the actual shape of wound.

Another factor is the movement of the person stabbed as discussed earlier. So, the modifying factors such as Tension of Langer's lines, skin elasticity, movement of the person, angle of the direction, the thrust during withdrawal made the shape of skin defect such variable that there is much difficulty to determine the shape or size of the weapon from the skin defect. The oval shape stab wound seen in this study should not indicate that the person stabbed with a oval shaped instrument as there is no such instrument usually used as homicidal weapon but actually this appearance occurred due to a weapon with a comparatively more sharp edge and a less sharp edge along with the interaction of the other modifying factors mentioned above.

\section{Conclusion}

The stab wound is deeper than it is long or wide. This means depth is the greatest dimension in case of Stab wound and that is where the danger lies as it is evident in this study. The statement of the witness if supplied in the inquest report and medico-legal examination of the wound when not in contradiction can be a valuable evidence.

\section{Conflict of Interests: None}

\section{Acknowledgement}

Thanks and all praise to Almighty Allah, the beneficial, the merciful for providing us enough energy and patience to complete this article. Our special thanks and gratitude toProfessors, Associate professors, Assistant professors \& all technical staffs of Department of Forensic Medicine, Sylhet MAG Osmani Medical College, Sylhet.

\section{References}

1. Reddy KSN. The Essentials of Forensic Medicine and Toxicology. 3rd edition. Hyderabad: Suguna Devi; 2014: 188-194.

2. Payne - James Jason, Jones Richard, B Karch Steven, Manlove John. Simpson's Forensic Medicine. 13thedition. Taylor \& Francis Group. 201;86.

3. Begum Asma, RabiulHuq Md., Begum Meherunnessa, Alam Azmeri, Akhter Gulshanara, TasminTamanna. A Case Report on Stab Injury. Delta Med Col J. 2014 Jan; 2(1): 36-38.

https://doi.org/10.3329/dmcj.v2i1.17795

4. Saukko P., Knight B. Knight's Forensic Pathology. 3rd edition. London: Hodder Arnold; 2004: 226-227.

https://doi.org/10.1201/b13642

5. Saukko P., Knight B. Knight's Forensic Pathology. 3rd edition. London: Hodder Arnold; 2004: 155-160.

https://doi.org/10.1201/b13642 
6. Parikh CK. Parikh's Textbook of Medical Jurisprudence, Forensic Medicine and Toxicology. 6th edition. New Delhi: VidhiSahityaPrakashan; 1999: 4.16.

7. Parikh CK. Parikh's Textbook of Medical Jurisprudence, Forensic Medicine and Toxicology. 6th edition. New Delhi: Vidhi Sahitya Prakashan; 1999:4.1184.121.

8. Nishimura Takeshi, Sakata Hiroyuki, Yamada taihei, Terashimamariko., Shirai Kunihiro, Yamada Isamu, et al. Different Patterns in Abdominal Stab Wound in the
Self-Inflicted and Assaulted Patients: An Observational Analysis of Single Center Experience. Kobe J Med Sci. 2017; 63(1): E17-E21. Published online 2017 Jan.

9. Swann I.J., Mac Millan R., Watson A.A. Archives of Emergency Medicine : A study of stab wounds Accident and Emergency Department, Royal Infirmary, Glasgow, Health Services Operational Research Unit, Department of Forensic Medicine Glasgow University, Glasgow, Scotland. Arch Emerge Med: first published as 10.1136/emj.2.1.31 on 1 March 1985. 